\title{
A CFD Analysis of Steam Flow in the Two-Stage Experimental Impulse Turbine with the Drum Rotor Arrangement
}

\author{
Kukchol Yun ${ }^{1, \mathrm{a}}$, L. Tajč² ${ }^{2}$ and M. Kolovratník ${ }^{1}$ \\ ${ }^{1}$ CTU, Department of Mechanical Engineering, 16607 Technická 4 Praha 6, Czech Republic \\ ${ }^{2}$ WBU, Department of Mechanical Engineering, 30614 Univerzitní 22 Plzeň, Czech Republic
}

\begin{abstract}
The aim of the paper is to present the CFD analysis of the steam flow in the two-stage turbine with a drum rotor and balancing slots. The balancing slot is a part of every rotor blade and it can be used in the same way as balancing holes on the classical rotor disc. The main attention is focused on the explanation of the experimental knowledge about the impact of the slot covering and uncovering on the efficiency of the individual stages and the entire turbine. The pressure and temperature fields and the mass steam flows through the shaft seals, slots and blade cascades are calculated. The impact of the balancing slots covering or uncovering on the reaction and velocity conditions in the stages is evaluated according to the pressure and temperature fields. We have also concentrated on the analysis of the seal steam flow through the balancing slots. The optimized design of the balancing slots has been suggested.
\end{abstract}

\section{Introduction}

At present a considerable increase in demand of industrial steam turbines exists. The Doosan Škoda Power tries to satisfy its customers also in this area and develops its own conception for industrial turbine construction. One of these conceptions is the drum rotor arrangement. Industrial turbines are generally characterized by a small output and it leads frequently to a problem of unacceptable increase in secondary loss of rotor blades. In the new conception this problem is restrained by the replacement of the classical rotor with big discs by the drum rotor (see Fig. 1).

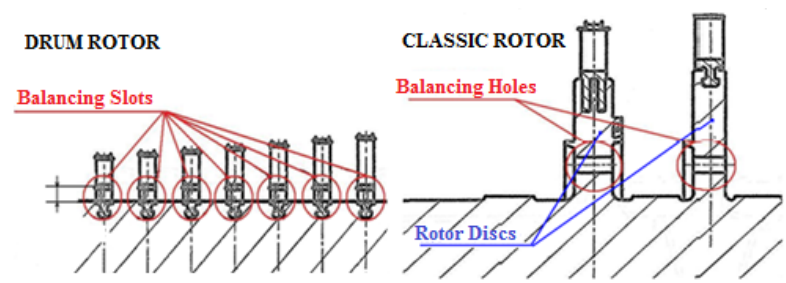

Figure 1. Schematic description of drum and classical rotor

This new concept of the rotor arrangement enables even for low output to use longer rotor blades, and in this way to reach lowering of their secondary losses. For construction reasons in the drum rotor arrangement large balancing holes, which are a common part of the classical impulse stage, cannot be realized. The balancing holes are made in the rotor disc and primarily serve to balance pressures in front of and behind the disc. Thus, the axial force affecting the rotor disc decreases. Another task of the balancing holes in the classical impulse stage is to extract the seal steam behind the rotor disc. The seal steam has generally higher temperature than the main steam flowing through the blade cascade. If this warmer seal steam is blown to the main flow part, the steam flow in the blade cascade is strongly influenced, mainly in the hub part of rotor blades. The change of the turbine stage reaction and deformation of a velocity triangle occurs.

The influence of blowing seal steam on the turbine stage efficiency was explored in detail by J. Synáč in his PhD thesis. From the findings it is evident that blowing seal steam always causes decrease in the turbine stage efficiency.

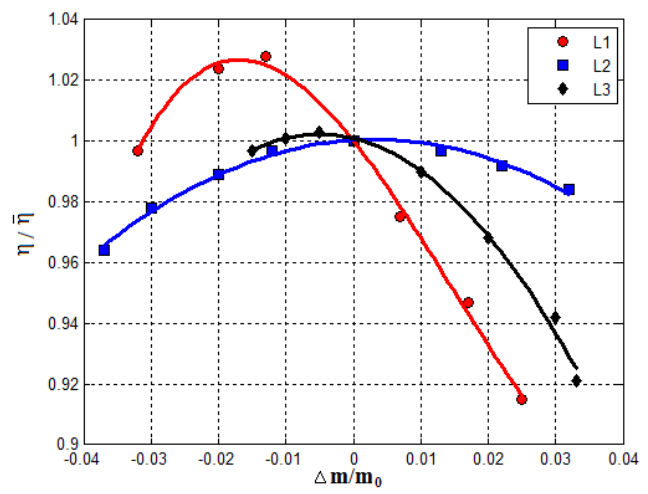

Figure 2. Dependence of efficiency in blown or extracted amount of steam for blades L1, L2 and L3

\footnotetext{
${ }^{\mathrm{a}}$ Kukchol Yun: kukchol.yun@gmail.com
} 
In Fig. 2 the dependences of the turbine stage efficiency on the blown or extracted amount of steam $\Delta m$ for various rotor blades L1, L2 and L3 are shown. These blades differ mainly in length. Specifically, blade L1 is the shortest and L3 the longest one.

As mentioned before, due to the construction limitations in the rotor with the drum arrangement it is not possible to make the large balancing holes. That's why, in the new conception these holes are replaced by slots of a small diameter, which are called balancing slots. These slots are part of each rotor blade and serve to extract seal steam behind the stage. Moreover, the shape of these slots is designed so that the flowing seal steam could produce a part of shaft power.

\section{Incomprehensibility of Experimental Results}

In Doosan Škoda Power laboratories many experiments have been carried out on the two stage impulse turbine with the drum rotor arrangement. While processing their results some difficulties were appeared. They were caused mainly by certain limitations while getting experimental data, uncertainty around the mass flow of steam through the balancing slots and by evaluations of representative pressure and temperature values in the individual turbine stages to calculate their efficiency. In addition, analysing experimental results brought controversial finding about the functionality of the balancing slots.

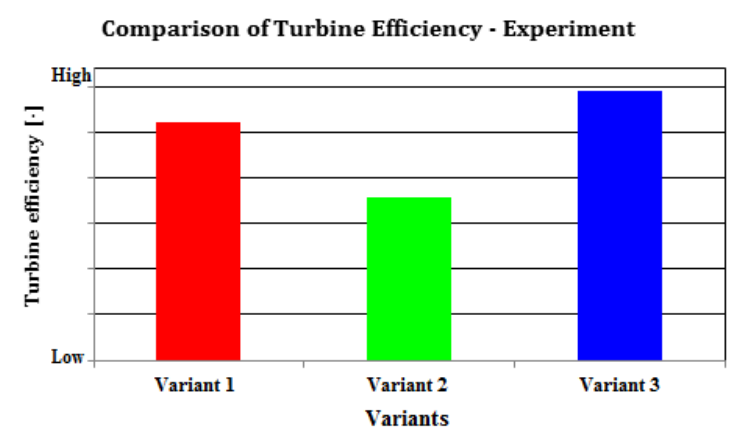

Figure 3. Comparison of turbine efficiency-Experiment

In Fig. 3 the turbine efficiencies are compared for variant 1,2 and 3, which differ in various operational setting of the $1^{\text {st }}$ and $2^{\text {nd }}$ stage of experimental turbine balancing slots (see Tab. 1).

Table 1. Operational setting of balancing slots for various calculation variants

\begin{tabular}{|c|c|c|}
\hline \multirow{2}{*}{ variant } & \multicolumn{2}{|c|}{ Balancing slots } \\
\cline { 2 - 3 } & $\mathbf{1}^{\text {st }}$ stage & $\mathbf{2}^{\text {nd }}$ stage \\
\hline variant 1 & uncovered & uncovered \\
\hline variant 2 & covered & covered \\
\hline variant 3 & covered & covered \\
\hline
\end{tabular}

Turbine efficiency for each variant is evaluated using measured values of pressures, temperatures, mass flow of steam and torque moments at experiments. It is obvious that the highest efficiency is measured for variant 3, where all balancing slots are covered and, thus, all seal steam is blown into the main flow parts of both stages. This fact is in direct contrast with Dr. Synáč's experimental results, which show negative influence of blowing of seal steam on the turbine stage efficiency. It is also noticeable that the lowest efficiency is achieved in variant 2 , where the balancing slots are covered only in the $1^{\text {st }}$ stage. Incomprehensible influence of the slot covering on the turbine efficiency is one of the reasons for implementing numerical analyses.

\section{CFD Calculations}

For better understanding of the steam flow not only through the balancing slots, but through the entire turbine, 3 CFD calculations modelling the same operational conditions that were applied at experimental turbine with the drum rotor arrangement were implemented. The calculation model with detailed description of the boundary conditions is shown schematically in Fig.4.

All calculations were realized in the ANSYS CFX using IAPWS IF97, describing the real steam properties.

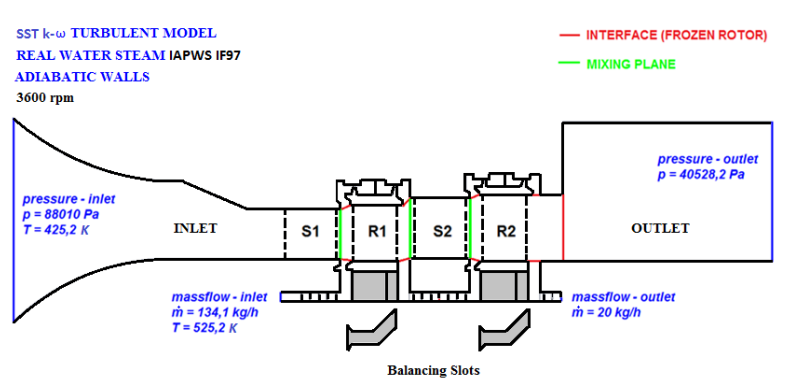

Figure 4. Calculation model

In Fig.5 the turbine efficiencies evaluated using results obtained from the CFD calculations are compared with ones measured from experiments. The comparison shows the same dependence of the turbine efficiencies on the operational settings of the $1^{\text {st }}$ and $2^{\text {nd }}$ stage balancing slots.

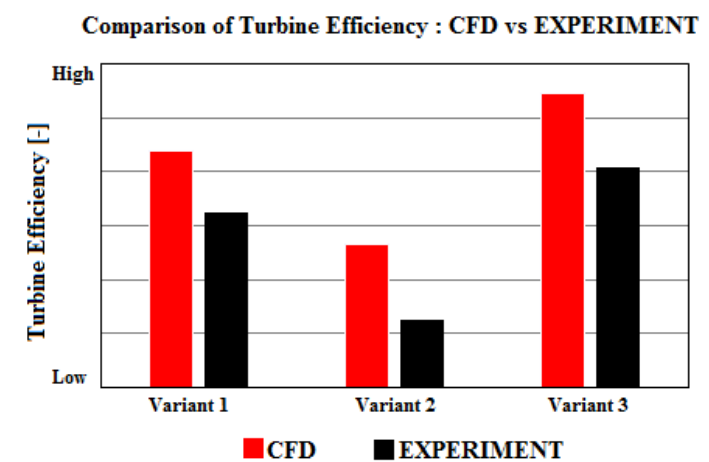

Figure 5. Comparison of turbine efficiency - CFD vs EXPERIMENT

Detailed analysis of CFD calculation results also shows negative influences of the seal steam blowing on 
aerodynamic parameters of the steam flow in the main flow part. As shown in Fig.6 and 7, seal steam blowing leads to increasing static pressure in front of the rotor and to slowing down the steam flow in the rotor cascade. This slowdown is more considerable mainly at the rotor blade hub and it is connected with the change of the angle $\alpha$ and $\beta$ respectively (see Fig. 8 and 9).

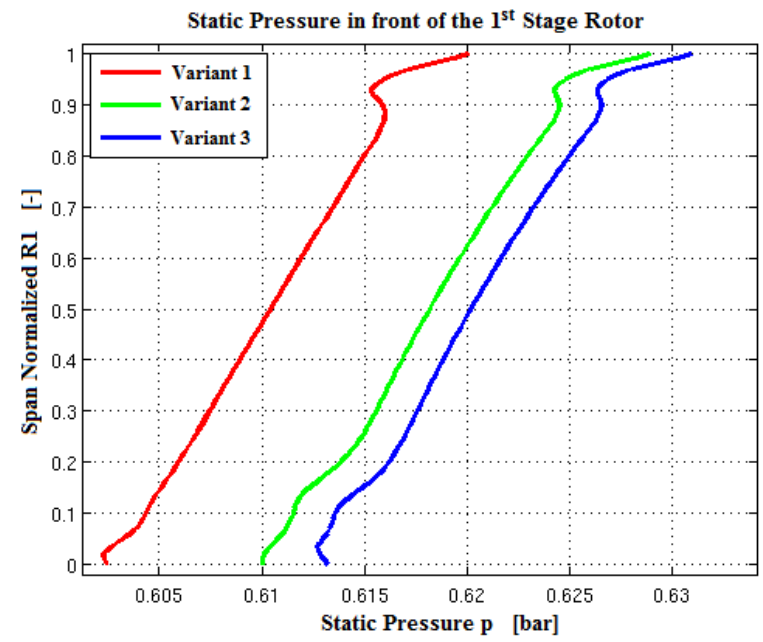

Figure 6. Static pressure in front of the $1^{\text {st }}$ stage rotor

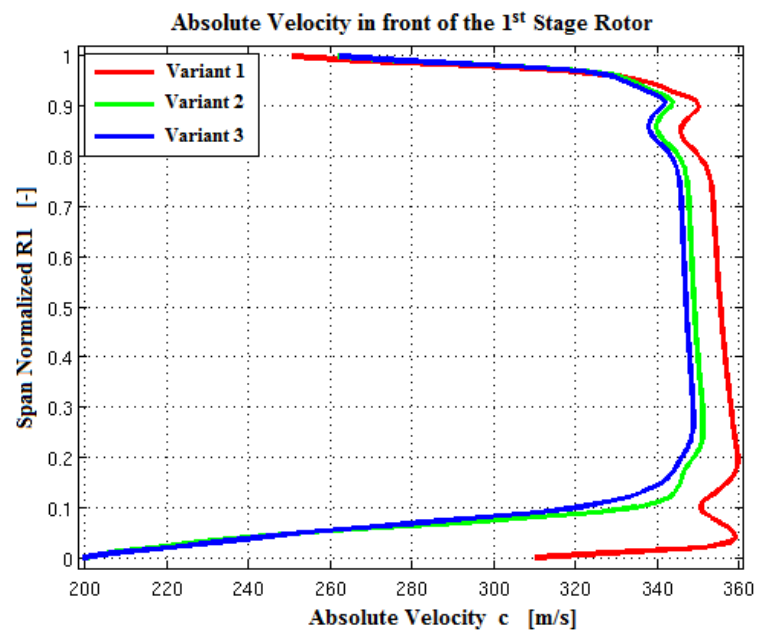

Figure 7. Absolute Velocity in front of the $1^{\text {st }}$ stage rotor

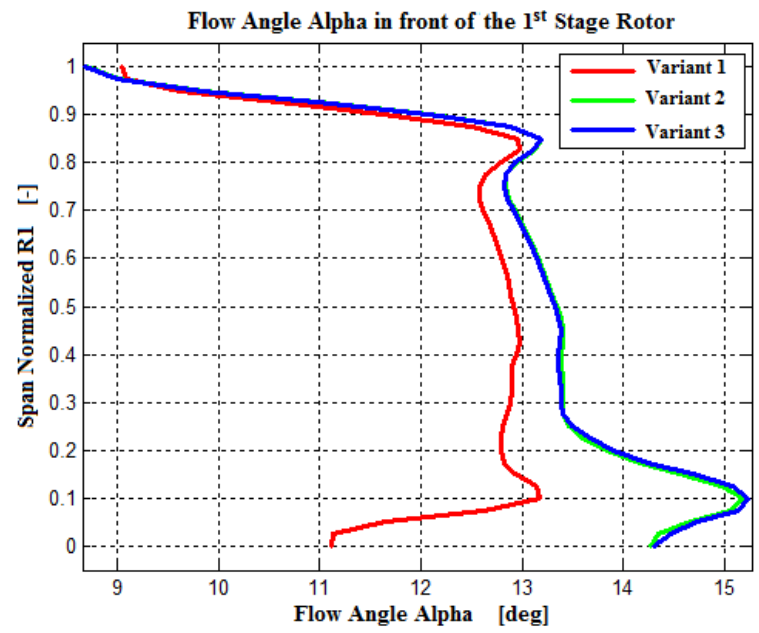

Figure 8. Flow Angle $\alpha$ in front of the $1^{\text {st }}$ stage rotor

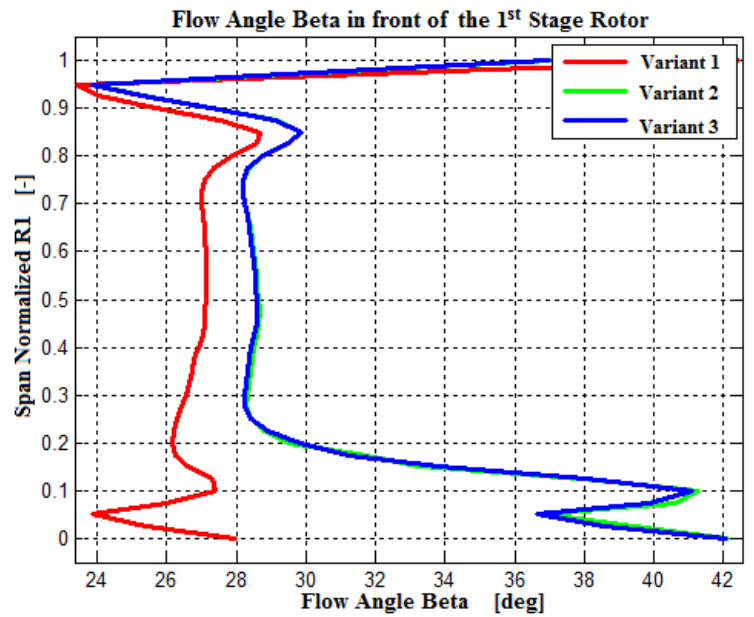

Figure 9. Flow Angle $\beta$ in front of the $1^{\text {st }}$ stage rotor

Seal steam has higher temperature than steam in the main flow part. Because of that, while blowing the seal steam into the main flow part, a change (increase) in reaction at the rotor blade hub occurs (see Fig. 10).

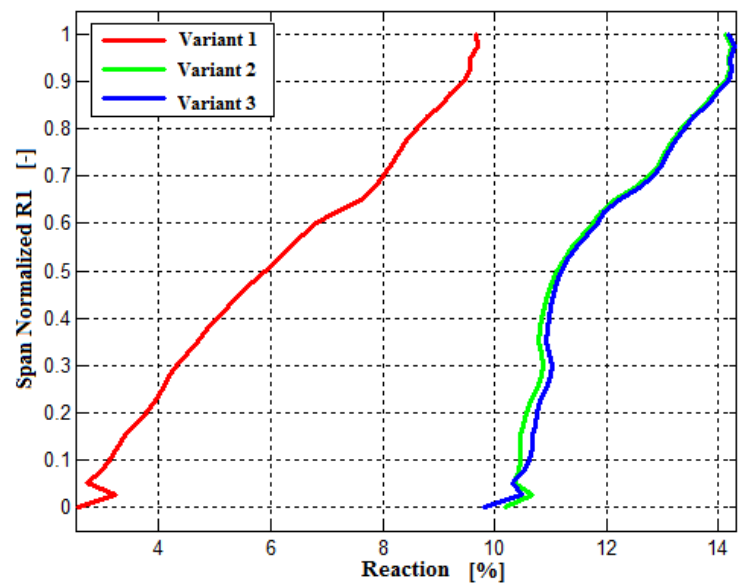

Figure 10. Reaction of the $1^{\text {st }}$ turbine stage

As the experimental turbine is an impulse turbine and has prismatic cylindrical blades, the above mentioned changes negatively influence on the turbine stage output. Thus, there are two contradictory conclusions.

The blowing seal steam leads to worsening of the aerodynamic parameters of steam in the main flow part and it will cause reduction of the turbine stage mechanical output. However, the highest efficiency is recorded in variant 3 , where seal steam is blown into the main flow part.

After a more detailed analysis of all implemented CFD calculation results it is evident, that the reason for this contradiction could be the fact that, at experiments the seal steam was considerably warmer than the main steam entering the turbine stage. Due to the technical reasons it was not possible to regulate the source of seal steam, its temperature was by $100 \mathrm{~K}$ higher than the main steam, which enters the turbine stage. Because of this considerable temperature difference, blowing seal steam represents a non-negligible ,intake“ of heat into the main flow part, even if its flux is relatively small comparing to the main steam flux. The in-this-way "heated" steam is 
processed in the following stage in variant 3 and in this way the loss of output in the previous stage, caused by worsening of aerodynamic parameters of the main steam, is compensated. In variant 2 , where only the balancing slots of the $1^{\text {st }}$ stage are covered, a part of the heated steam is extracted by uncovered balancing slots of the $2^{\text {nd }}$ stage without using its potential to produce shaft power. This extracting of better quality steam can provide answers to the question, why the efficiency of this variant is calculated as the lowest.

Such extremely high temperature of seal steam is not practically common. As a matter of the fact, the seal steam temperature is almost as high as the steam temperature in the main flow part.

To confirm the correctness of the given assumption, calculations are done of other three variants (variant 1a, $2 \mathrm{a}$ a $3 \mathrm{a}$ ). These new calculation variants differ from the previous ones by boundary condition for the seal steam inlet. In this case the seal steam has the same pressure and temperature as the main steam entering the turbine stage.

The subsequent processing of these CFD calculations confirms the correctness of the assumption. A direct proof is provided by comparison of the turbine efficiency for variants 1a, $2 \mathrm{a}$ and $3 \mathrm{a}$ (see Fig. 11).

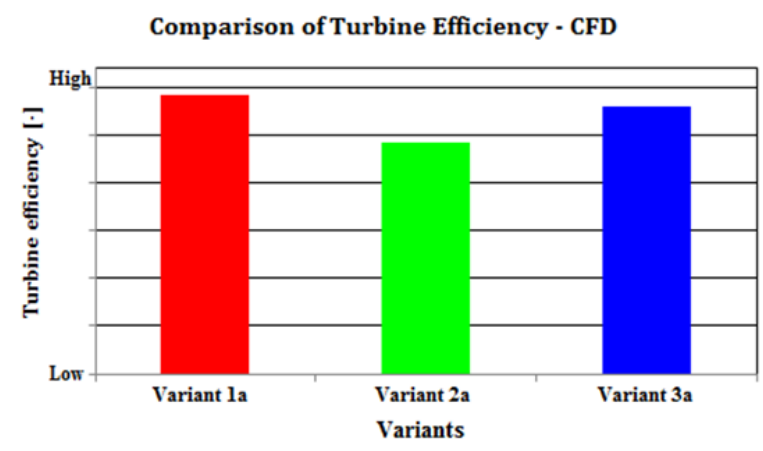

Figure 11. Comparison of turbine efficiency-CFD

This time the highest efficiency is reached in variation 1a, where all balancing slots of both stages are uncovered. It explains why the results gained from experiments do not correspond with the older theoretical findings.

\section{Steam Flow through Balancing Slots}

The results of CFD calculations show that extracting seal steam through balancing slots is, from the viewpoint of turbine stage efficiency, more favourable than steam blowing into the main flow steam. That's why considerable attention is devoted to examination of steam flow through the balancing slots.

In Fig. 12 steam flow through the balancing slots is presented.

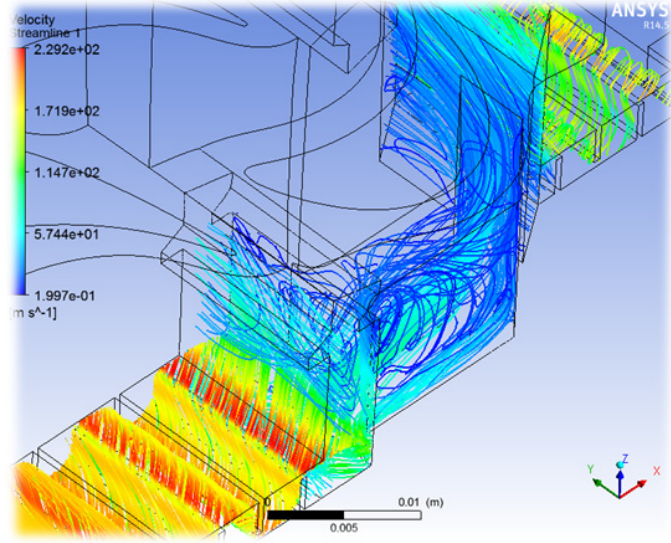

Figure 12. Steam flow through balancing slots

A detailed analysis shows that flow cross-sectional areas of existing balancing slots are oversized. This means that not only the seal steam, but also a part of the main flow steam goes through the balancing slots. Since balancing slots are not able to effectively gain energy from the steam flow like the blade grid, extracting main steam is not desirable. Moreover, we found out that the velocity ratio in front of and behind the balancing slots is very different from the ratio in front of and behind the rotor cascade of the turbine stage.

In Fig. 13 velocity triangles for the balancing slots are compared with velocity triangles for rotor cascade.

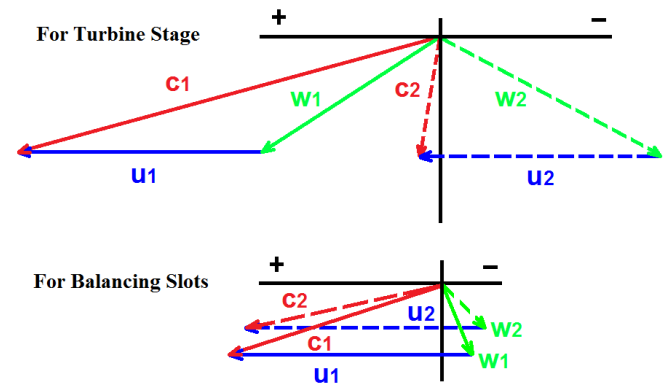

Figure 13. Velocity triangles for the turbine stage and balancing slots

Due to this difference local increase of pressure occurs on the suction side of balancing slots (see Fig. 14).

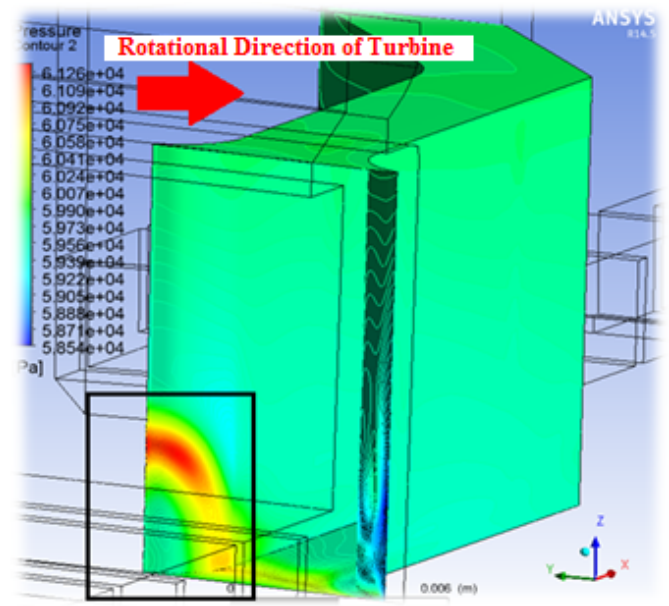

Figure 14. Occurrence of local increase of pressure on the suction side of balancing slot 
Several possibilities to improve functioning of the balancing slots are founded.

The first possibility is optimization of flow crosssectional area of the balancing slots. The steam flow going through the balancing slots mainly depends on their flow cross-sectional area. Even more optimization of the flow cross-sectional area can prevent extraction of steam from the main flow part, which leads to reduction of turbine stage output.

Another possibility can be the design of more suitable inlet shape of the balancing slots. Inlet shape of the balancing slots that fit better the flow ratios can reduce the occurrence of local increase of pressure on their suction side. This reduction could cause the steam, which flows through the balancing slots to produce shaft power more effectively (see Fig. 15).

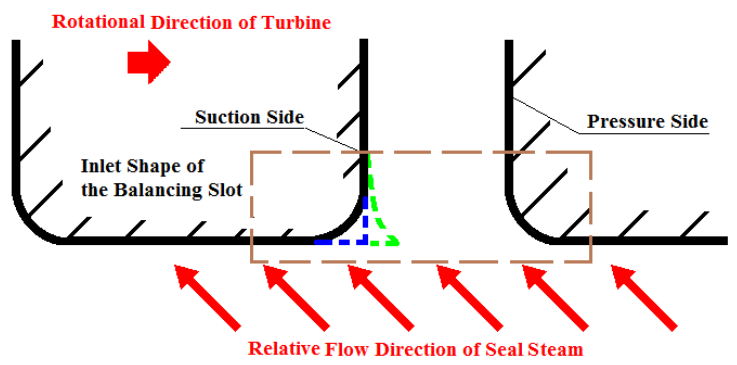

Figure 15. Possible inlet shapes of balancing slot

Acceleration and change of the flow angle at the balancing slots outlet can also lead to improvement of gaining shaft power from the seal steam and increase in the turbine stage efficiency. As shown in Fig.13, acceleration and change of flow angle at cause lowering of the peripheral component of the absolute velocity $\mathrm{C}_{2 \mathrm{u}}$. It is obvious from the Euler Turbine Equation that decreasing this component leads to increase of mechanical output.

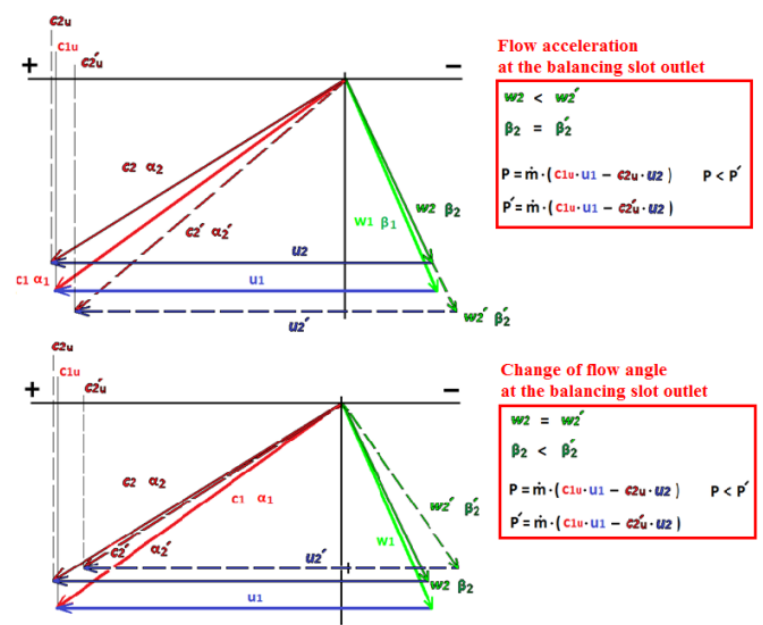

Figure 16. Steam flow acceleration and change of flow angle at the balancing slots outlet

\section{Conclusion}

To clarify some uncertainties of experimental results and to understand better the steam flow through the entire experimental turbine, a large range of CFD calculations was implemented.

Detailed processing of obtained results brought a hypothesis about the cause of these uncertainties and consequently confirmed it.

The results of the CFD calculations further showed that extracting seal steam through balancing slots in impulse turbine with drum rotor arrangement is, from the viewpoint of its efficiency, more favourable than it's blowing into the main flow part.

After a detailed analysis of steam flow through the existing balancing slots some options for their shape optimization were suggested.

Final dimension and shape of the optimized balancing slots will be a result of the combination of these proposed options of modification.

\section{References}

1. A. Mecke, I. Lee, J.R. Baker jr., M.M. Banaszak Holl, B.G. Orr, Eur. Phys. J. E 14, 7 (2004)

2. M. Ben Rabha, M.F. Boujmil, M. Saadoun, B Bessaïs, Eur. Phys. J. Appl. Phys. (to be published) 